\title{
PROVOCĂRI DE DIAGNOSTIC ÎN TAHICARDIA VENTRICULARĂ LA COPIL
}

\author{
Constantin Iordache, Andreea-Simona Holoc, Claudia-Mihaela Toma, \\ Mihaela Grecu, Alina-Costina Luca \\ ${ }^{1}$ Clinica I Pediatrie, Spitalul de Pediatrie ,Sf. Maria“, \\ Universitatea de Medicină şi Farmacie „, Gr. T. Popa “, Iaşi
}

\begin{abstract}
REZUMAT
Aritmiile cardiace primare sunt mult mai puțin frecvente la sugari şi copii decât la adulți, simptomele prezentate putând fi vagi şi nespecifice. Deşi urgențele reale din cauza aritmiilor instabile la copii sunt rare, este important să se identifice şi să se gestioneze în mod corespunzător cazurile. Prezentăm cazul unui copil, care se internează pentru simptomatologie respiratorie, la examenul clinic decelându-se o frecvență cardiacă de 214 bpm. Copilul a devenit progresiv anxios, prezentând efort respirator. Studiul electrocardiogramei a stabilit diagnosticul de tahicardie ventriculară fasculară anterioară cu tendința la permanentizare. Evoluția a fost favorabilă după efectuarea cardioversiei electrice şi tratament preventiv cu Verapamil.
\end{abstract}

Cuvinte cheie: tahicardie ventriculară, copil, cardioversie electică

Tahicardia ventriculară reprezintă o succesiune de mai mult de 4 complexe originare distal de bifurcația fasciculului Hiss în țesutul specializat de conducere sau în miocardul ventricular cu o frecvență ce variază între 120-250/min., având drept mecanism fie tulburări în formarea impulsului, fie fenomene de reintrare (1).

\section{PREZENTARE DE CAZ}

Pacient B.B., în vârstă de 6 ani 5 luni se prezintă pentru simptomatologie respiratorie: tuse productivă şi dispnee expiratorie, tratată la domiciliu timp de 5 zile cu Klacid şi Eurespal. Din antecedentele personale patologice reținem multiple infecții de căi aeriene superioare care nu au necesitat internare.

Examenul clinic:

- Stare generală influențată, $\mathrm{T}=+1,23 \mathrm{DS}$, $\mathrm{G}=+0,87 \mathrm{DS}, \mathrm{PC}=+1,5$;

- Paloare tegumentară, discretă congestie faringiană;

- Pulmonar - murmur vezicular aspru, raluri subcrepitante bilateral bazal, FR $=32 \mathrm{r} / \mathrm{min}$, $\mathrm{SaO} 2(-)=99 \%$;
- Cardiac - zgomote cardiace ritmice, tahicardice, $\mathrm{FC}=214 \mathrm{~b} / \mathrm{min}$;

Restul aparatelor şi sistemelor au fost în limite normale. Datele de laborator au fost în limite normale.

Datorită frecvenței cardiace crescute se decide efectuarea unei electrocardiograme (Fig. 1) care decelează o FC: 211/min, ritm regulat, axa complexului QRS -90 grade, durata complexelor QRS este de $0,13 \mathrm{sec}$, cu succesiune regulată, monomorfă; cu disociație artrio-ventriculară şi aspect de bloc de ram drept asociat cu hemibloc stâng anterior.

Diagnosticul de etapă în urma electrocardiogramei a fost dificil de stabilit. Aşadar, s-au exclus:

- Tahicardia paroxistică supraventriculară condusă aberant: deşi avem prezența complexului RS (V1-V6), durata complexelor RS este peste $100 \mathrm{~ms}$ în derivațiile precordiale, prezența disociatiei atrio-ventriculare în $\mathrm{V} 1$, prezența undei $\mathrm{R}$ inițiale în a VR $>40 \mathrm{~ms}$, susțin diagnosticul de TV.

- Tahicardie atrială cu complexe QRS largi

- Fibrilație ventriculară: ritmul ventricular dezorganizat 


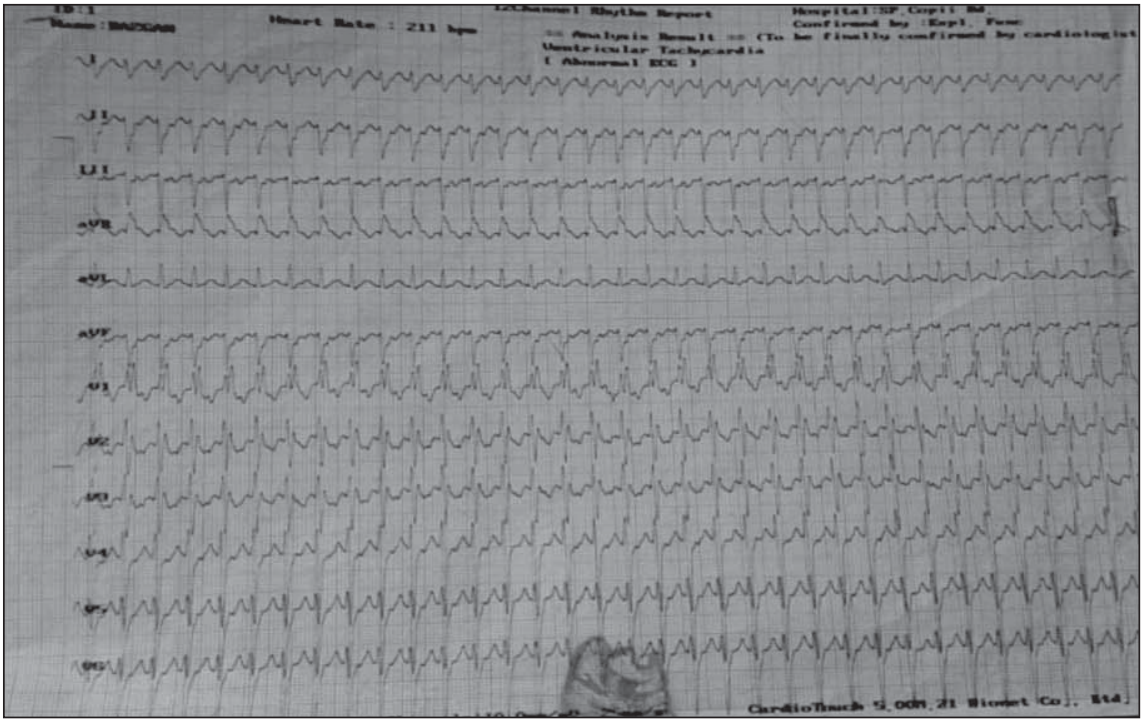

FIGURA 1. Electrocardiograma: tahicardie ventriculară fasciculară anterioară
- Flutter ventricular: aspect sinusoidal prin care ORS pare simetric de o parte şi de alta a liniei izoelectrice.

- TV polimorfă

- Ritm idioventricular accelerat: este o tahicardie ventriculară monomorfă, cu frecvență în cele mai multe cazuri sub 120/min, repetitivă prin automatism accelerat patologic.

Radiografia cardio-toracică (Fig. 2) relevă desen pulmonar accentuat hilio-bazal bilateral şi cord cu rectitudinea arcurilor stângi (uşoară cardiomegalie $\mathrm{IC}: 1,3)$.

Ecocardiografia (Fig. 3) revelă disfuncție diastolică ventriculară, refluare tricuspidiana gr. III, foramen ovale patent, asincronism de contracție a septului interventricular, fracția de ejecție: $60 \%$, Fracția de scurtare: $31 \%$. Modificările structurale ale cordului nu reprezintă un punct de plecare al tahicardiei ventriculare, ci mai degrabă o consecință a modificărilor electrofiziologice.

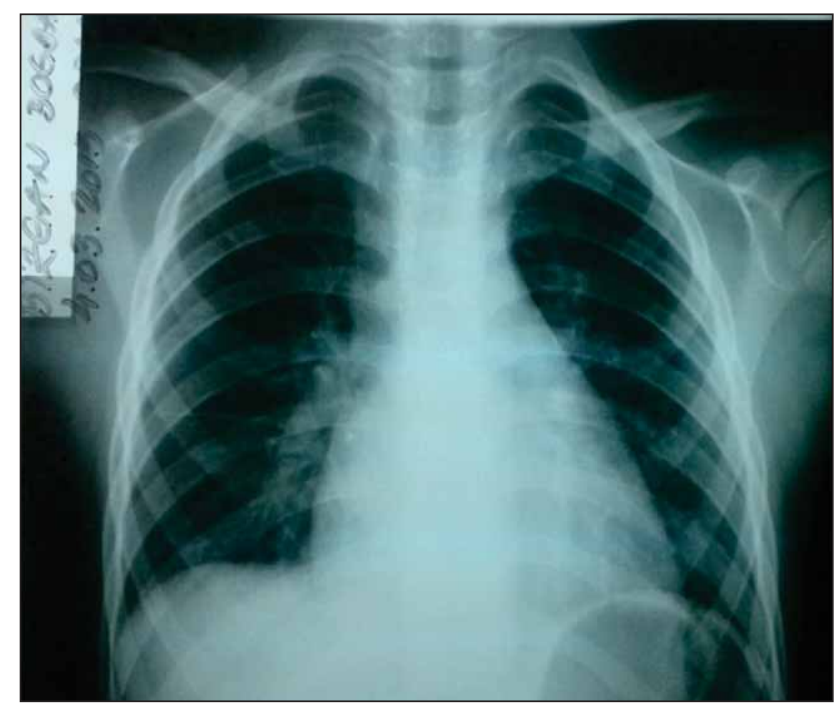

FIGURA 2. Radiografie cardio-toracică
S-a stabilit diagnosticul de tahicardie ventriculară fasciculară anterioară cu disociație atrioventriculară, cu tendința la permanentizare, bloc de ram drept cu hemibloc stâng anterior. A primit tratament cu antibiotic, simptomatice, adenozină $2,5 \mathrm{mg}$ inițial, apoi $5 \mathrm{mg}$, amiodaronă $350 \mathrm{mg}$ x 2/zi, tahicardia persistând după 24 de ore sub medicația antiaritmică. Se decide efectuarea cardioversiei întrucât statusul funcțional al copilului se degradează progresiv: dispneea expiratorie s-a accentuat, extremitățile fiind reci şi transpirate. S-a practicat anestezie generală cu Midazolamum 1 mg i.v. şi Revafil 20 mg i.v, apoi s-a aplicat şoc electric extern $50 \mathrm{j}$ bifazic cu pasaj în ritm sinusal 88/min. (Fig. 3)

S-a continuat monitorizare zilnică a EKG; pacientul primind Verapamil $40 \mathrm{mg} / \mathrm{zi}$. În evoluție, sub tratamentul medicamentos, starea generală a copilului este bună, menținând o frecvență cardiacă de $100 / \mathrm{min}$.

EKG-ul la externare relevă ritm sinusal 100, min, axa QRS: +100 grade. $P Q=0,14 \mathrm{sec}$. Bloc de ram drept, unde T negative în DII, DIII, AVF şi în derivațiile precordiale stângi (sugerând o uşoară ischemie datorată scăderii debitului cardiac).

La internările de control, starea pacientului este bună, frecvența cardiacă fiind de 90 bpm, blocul de ram drept persistând.

\section{DISCUȚII}

Tahicardia ventriculară este foarte rară la copil, dar impactul acestei patologii asupra prognosticului este extraordinar de mare. Acesta este cu atât mai important cu cât frecvența cardiacă este mai crescută, diastola ventriculară este redusă, contribuţia atrială lipseşte (disociație atrio-ventriculară), 


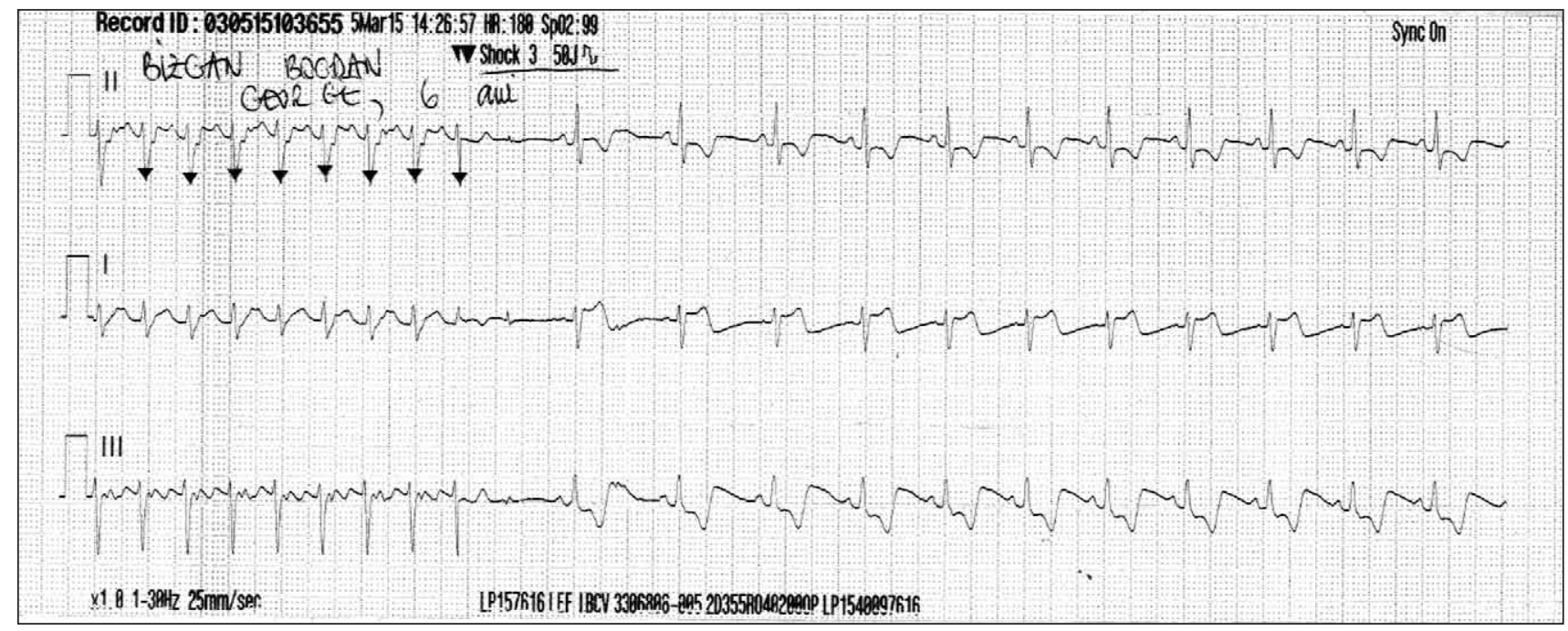

FIGURA 3. EKG în timpul cardioversiei electrice cu 50 j bifazic

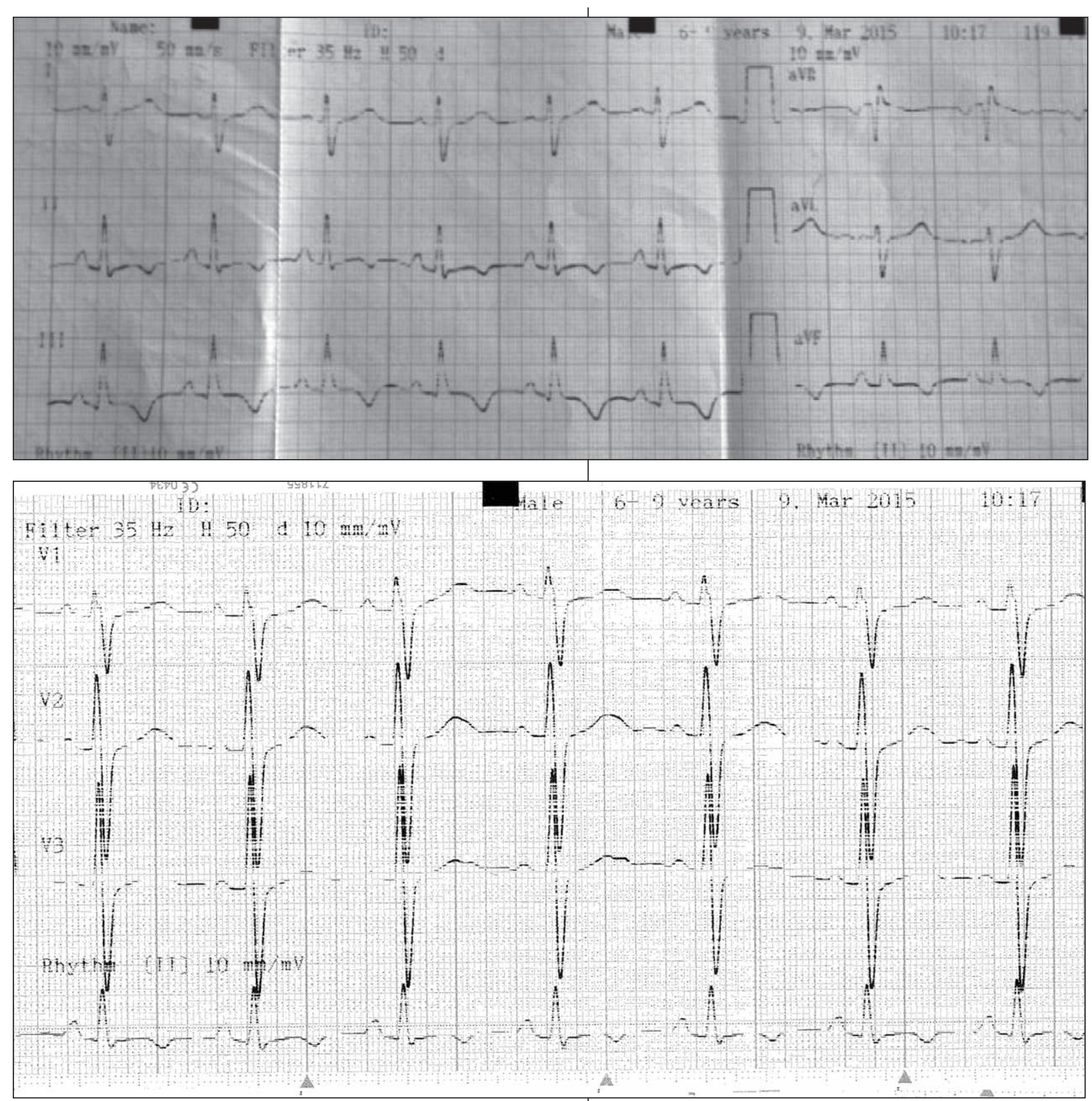

FIGURA 4. EKG la externare: FC:100/min, BRD 
ducând la alterarea perfuziei miocardice şi ulterior la moarte subită $(2,3)$.

Tahicardia ventriculară monomorfă incesantă este caracterizată prin prezența de secvențe de activitate ventriculară cu aceeaşi morfologie, care devine permanentă, fiind imposibil de întrerupt sub medicaţie (4). Aceasta apare pe un strat patologic (boli cardiace congenitale, hipertrofie ventriculară, cardiomiopatii hipertrofice obstructive, cardiomiopartie aritmogenă a ventriculului drept, infarct miocardic acut, sarcoidoză, Boala Chagas, sindrom Brugada, sindrom QT lung) (11) degradându-se în fibrilație ventriculară (5), sau pe cord normal, fiind foarte bine tolerată, dar poate detemina în timp cardiomiopatie dilatativă (6).

Prin algoritmul lui Verekei putem diferenția o tahicardie ventriculară de o tahicardie paroxistică supraventriculară prin:

- prezența unei unde R iniţiale în aVR; durata unei unde $\mathrm{r}$ sau q iniţiale de peste $40 \mathrm{~ms}$ în aVR; aspect „crestat"“ al pantei inițiale a complexului QRS predominant negativ în aVR

- raportul velocitate-activare ventriculară $(\mathrm{Vi} /$ $\mathrm{Vt}) \leq 1$ (panta primelor $40 \mathrm{~ms}$ din complexul QRS a lui aVR/panta ultimelor $40 \mathrm{~ms}$ din complexul QRS a lui aVR) (7).

Dacă starea pacientului este stabilă şi nu este însoțită de degradare hemodinamică, după diagnos-
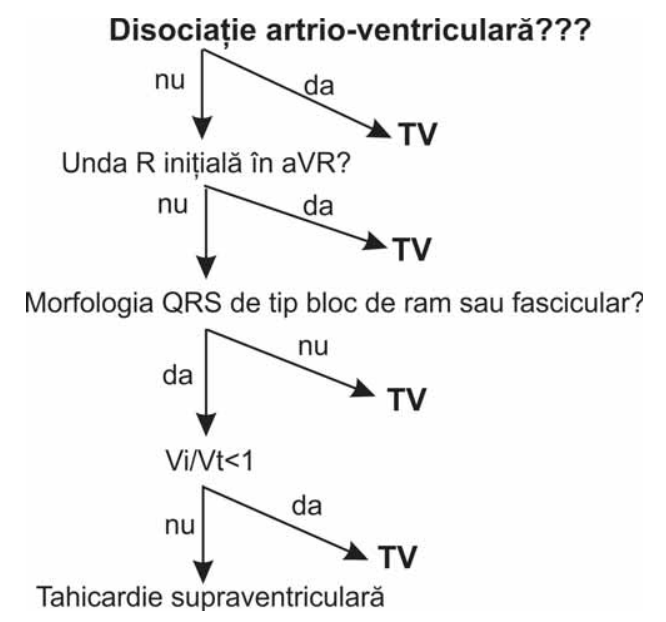

FIGURA 5. Algoritmul Vereckei de diagnostic al tahicardiei ventriculare ticul corect al tahicardiei ventriculare se încearcă cardioversie medicamentoasă cu Amiodarona 5 $\mathrm{mg} / \mathrm{kgc}$ iv sau Procainamida $15 \mathrm{mg} / \mathrm{kgc}$ iv (nu se administrează niciodată Amiodarona şi Procainamida împreună) sau Lidocaina $1 \mathrm{mg} / \mathrm{kgc}$ bolus. Dacă cardioversia medicamentoasă nu a avut succes, atunci se recurge la cardioversie electrică sincronă bifazică $0,5-1 \mathrm{~J} / \mathrm{kgc}$ (se poate încerca $2 \mathrm{~J} / \mathrm{kgc}$ dacă doza inițială a fost ineficientă); aceste manevre se fac numai după sedare în prealabil.

Postcardioversie, în tahicardia ventriculară fasciculară, se realizează profilaxia recidivelor prin administrarea de Verapamil per os $(9,10)$. Dacă reapar simptomele sau există o intolerabilitate la medicație se pot aplica metode invazive de tratament:

- cardiodefibrilator implantabil (în cazul în care există condiţii familiale cu risc crescut de moarte subită: sindrom de QT lung, sindrom Brugada; tahicardie ventriculară cu afectare hemodinamică şi fracție de ejecție $<35 \%$ );

- tratamentul ablativ prin radiofrecvență (indicată mai ales în tahicardia ventriculară pe cord normal, dar şi în anumite patologii particulare: tahicardia fasciculară, tahicardii idiopatice, displazia aritmogenă de ventricul drept) (8);

- tratament ablativ prin alte forme de energie: crioablația, microundele, laserul şi ultrasunetele.

\section{CONCLUZII}

Tahicardia ventriculară poate reprezenta o patologie individuală, pe cord normal constituit diferit organic sau structural. Toleranța bună a simptomatologiei şi lipsa anomaliilor cardiace care ar putea declanşa tahicardia ventriculară au condus la instituirea medicației antiaritmice, dar fără succes terapeutic. Cardioversia electrică determină restabilirea traseului electrocardiografic şi normalizarea frecvenței cardiace, cu o evoluție favorabilă pe termen lung. 